\title{
Preparation and Characterization of Aluminium Wire Mat Reinforced Polyester Composite
}

\author{
Rajib Chandra Das ${ }^{1 *}$, Arif Ul Islam¹, Sanchita Dewanjee1, Tanjima Akhter², Farzana Sultana Rafi², \\ Susmita Mondal ${ }^{3}$ \\ ${ }^{1}$ Department of Applied Chemistry and Chemical Engineering, Noakhali Science and Technology University, Sonapur, Noakhali, \\ Bangladesh \\ ${ }^{2}$ Department of Applied Mathematics, Noakhali Science and Technology University, Sonapur, Noakhali, Bangladesh \\ ${ }^{3}$ Department of Pharmacy, Noakhali Science and Technology University, Sonapur, Noakhali, Bangladesh \\ Email: *rajib.acce@gmail.com
}

How to cite this paper: Das, R.C., Ul Islam, A., Dewanjee, S., Akhter, T., Rafi, F.S. and Mondal, S. (2019) Preparation and Characterization of Aluminium Wire Mat Reinforced Polyester Composite. Advances in Materials Physics and Chemistry, 9, 48-56.

https://doi.org/10.4236/ampc.2019.94005

Received: March 13, 2019

Accepted: April 16, 2019

Published: April 19, 2019

Copyright $\odot 2019$ by author(s) and Scientific Research Publishing Inc. This work is licensed under the Creative Commons Attribution International License (CC BY 4.0).

http://creativecommons.org/licenses/by/4.0/

\begin{abstract}
Aluminum wire mat reinforced polyester composite has been studied as an alternative structural material. The physical and mechanical properties of the composite such as tensile strength, flexural strength, water absorption, hardness illustrated the competency of the developed composite. It was found that percent water absorption is very low for the resultant studied composite. However, water absorption increased very slowly when metal mat layers were increased. Furthermore, mechanical strength of the composite was increased as mechanical properties: tensile strength, flexural strength, hardness and stiffness of this composite increased with the increase in the number of metal mat layer in the composite. This study suggested the use of this composite as an unbeaten alternative structural material to conventional materials.
\end{abstract}

\section{Keywords}

Aluminum Reinforcement, Polyester Matrix, Metal Polyester Composite

\section{Introduction}

Metal reinforced polyester composite has increasingly drawn the attention of the researchers during the last decades. Concepts are changing for structural material used in house building construction, household materials, transport material, electronics, etc. Materials with lower cost, long shelf life, higher strength and mach inability are the pre-requisite during procuring new structural materials. The researchers focus on finding an alternative structural material which is me- 
chanically strong but light in weight. In this respect a common approach is to produce composite materials by varying a range of matrix materials and reinforcing agents. Composites are classified in different ways, according to the distribution of the material that is geometry composites can be classified as particulate, laminated and fibrous. On the other hand, according to the matrix material and reinforcing agents composites can be classified as metal matrix composite, polymer matrix composite, ceramic matrix composite, etc. [1]. A single homogenous material has its inherent deficiencies in mechanical performance [2]. When they are stiff and sufficiently hard, they are brittle and hardly processible and vice versa. The contribution of a composite interface, to the mechanical performance of the resultant material is mainly related to its potential for transferring mechanical strength from matrix to the reinforced material during loading [3].

In this project, the metal mat reinforced polymer (MMP) composites were developed where an aluminum metal mat of high strength reinforcing was combined with a polymer (polyester resin) matrix. Aluminum is a reasonably soft, resilient, lightweight, ductile, and malleable metal. It shows impressive protective performance against corrosion as a layer of aluminum oxide forms on its surface which prevents it from corrosion. This process is termed as passivation [4]. Polyester resins are readily available and have been commonly used in composite materials due to their dimensional stability, desirable mechanical performance and high chemical resistance. However, polyester resin is very brittle and cannot be used without any reinforcement [5]. Therefore, it is important to choose a suitable reinforcement which can improve the mechanical properties of the composite materials for construction and household purposes. To this end, the aim of this study is to develop an aluminum wire mat reinforced polyester composite and estimate its competency in the respect of mechanical properties.

\section{Materials and Methods}

\subsection{Materials}

The materials used for the sample preparation were polyester resin, aluminum wire mat, methyl ethyl ketone per oxide (MEKP) as hardener, and styrene. All the materials were of commercial grade and purchased from the local market of Dhaka, Bangladesh.

\subsection{Methods for Sample Preparation}

Metal mat was cut as per desired size (in this study metal wire was cut into a dimension of $5 \mathrm{~cm}$ long $5 \mathrm{~cm}$ wide). Unsaturated polyester resin and styrene we remixed in a ratio of 9:1. Methyl ethyl ketone was added in an amount of 1.5 wt $\%$ of polyester resin and styrene in an amount of $10 \%$ of polyester resin was added as hardener with continuous stirring for half an hour. Then the mixer was poured into the mould to make zero layered metal mat reinforcement polyester composite. For the single layered, double layered and triple layered metal rein- 
forcement composite, the metal mat was put on the mould by a support and when the mixer was poured on the mould, the mat was at the center of the mixer. After 36 hours of drying the composite specimen was ready for further testing as shown in Figure 1. These composite was then cut into desired dimensions [6] [7].

\subsection{Characterization}

\subsubsection{Water Absorption Test}

Water absorption is the amount of water absorbed by the dry sample soaked in water for a certain time period. First of all, the test specimen was cut into a dimension of 10 to $12 \mathrm{~mm}$ long, 5 to $6 \mathrm{~mm}$ wide and 3 to $4 \mathrm{~mm}$ high According to ASTM D1505-18 [8]. The sample was kept in a container filled with distilled water $\left(23^{\circ} \mathrm{C}\right)$ and soaked in the water for around 120 hours for measuring water absorption according to ASTM D570-98 (2018) [9]. Percent water absorption was measured by every 24 hours.

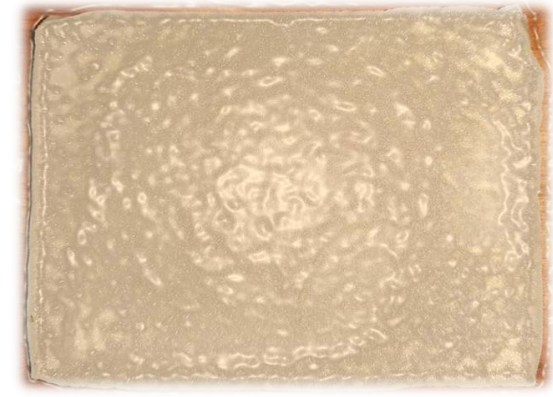

(a)

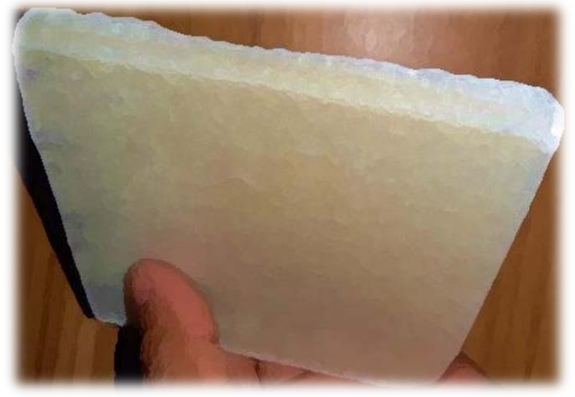

(b)

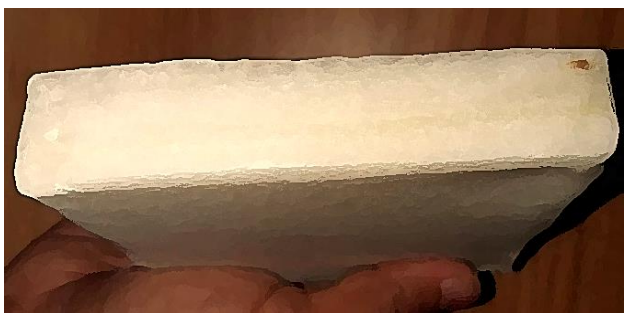

(c)

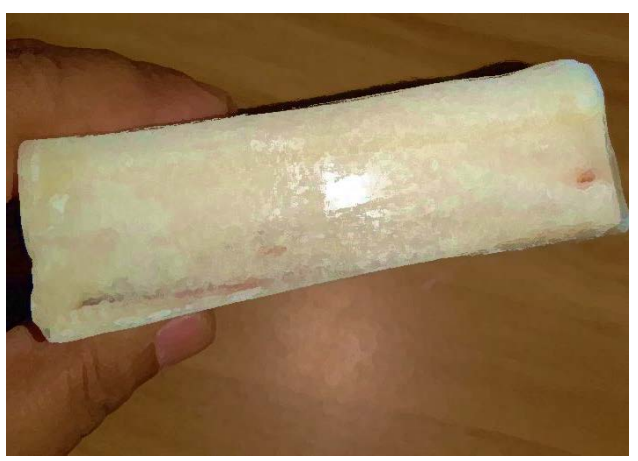

(d)

Figure 1. Aluminum wire mat reinforced polyester composite (a) zero metal mat (b) single metal mat (c) two metal mat (d) three metal mat. 
Percent water absorption was calculated by using the following equation:

$$
\text { Percent water absorption }=\frac{\text { Wet Weight }- \text { Dry Weight }}{\text { Dry Weight }} \times 100
$$

\subsubsection{Tensile Strength Test}

Tensile strength is a very important mechanical property of any materials. Mathematically it is the ratio of applied load to the cross-sectional area. Tensile strength is a measure of performance that is how much a material can resist an applied force. Specimen for tensile strength test was prepared according to ASTM D638-02a [10]. Tensile strength test was carried out according to the standard method described in ASTM D638-14 [7] and calculated by using equation

$$
\text { Tensile strength }=\frac{\text { Applied load }}{\text { Cross sectional area of the load bearing area object }}
$$

Percent Elongation (PE) is reported with tensile strength that is the measure of ductility and is defined as the ratio of maximum elongation with original gage length.

$$
\text { Percent Elongation }=\frac{\text { Final gage length }- \text { Original gage length }}{\text { Original gage length }} \times 100
$$

\subsubsection{Flexural Strength Test}

Flexural strength is a property of material defines as the stress that is applied just before rapture of the materials. That is the pressure just before bending of any material are termed as flexural strength.

Specimen for flexural strength test was prepared according to ASTM D 790-02 [11]. The flexural strength test was then carried out by using the standard method described in ASTM D790-17 [6] and calculated by using the following equation

$$
S=\frac{3 P L}{2 B D^{2}}
$$

where, $S=$ stress in the outer fibers at mid span, in MPa; $P=$ load at a given point; $L=$ length of the tested specimen in $\mathrm{mm} ; B=$ width of the tested specimen in $\mathrm{mm} ; D=$ Depth of tested specimen in $\mathrm{mm}$.

\subsubsection{Rebound Hardness Test}

When impacting a metal sample with a magnet the hardness of the metal was calculated in terms of energy loss by the magnet. In the reaction the magnetic body rebounded faster when impacting a hard sample than softer ones. In the case of the magnetic impact body a voltage arised that reduced the velocity as it was moving through the measuring coil. When measuring the velocity of the magnetic impact body, the rebound hardness was calculated by using the following equation [12] [13].

$$
\mathrm{HL}=\frac{1000 V_{i}}{V_{r}}
$$


where, HL is the rebound hardness, $V_{i}$ is the velocity before impact; $V_{r}$ is the velocity after the impact.

\section{Results and Discussion}

\subsection{Sorption Behavior}

Result showed that percent of weight gain due to water absorption is very low for the current studied samples. A comparative study of water absorption of the resulting composites is shown in Figure 2. It shows that the water absorption values increased with increasing the metal mat layers in the composite. That is water absorption was found minimum (0.21\%) for zero layered composite and then water absorption increased with subsequent addition of metal mat layer. Water absorption found maximum for three metal mats layered composite. There are various models in order to describe the sorption behavior of materials which based on the Fick's law of diffusion [14]. According to Fick's law of diffusion, moisture absorption increase with the thickness of the material. However, after a certain time the rate of water absorption rate decreased sharply due to the saturation attained. Water absorption rate in cellulose based composite is higher than metal reinforced composite, because cellulose itself absorbs a large amount of water whereas metal doesn't absorb any water [14]. When a composite absorbs much water then its mechanical properties are adversely hampered. In this respect the studied sample will serve better.

\subsection{Tensile Strength}

Among all working samples, the tensile strength for the three layered metal composite was found to be the highest (15.27 MPa) and the lowest (10.60 MPa) for zero layered metal mat-polyester composite respectively. Therefore, the tensile strength of the sample increased with the increase in the number of metal mat layers in the composite, as shown in Table 1. It is well established that presence of reinforcement increases the strength of composite and higher fiber content increases strength higher than short fiber content [15].

\subsection{Percentage Elongation}

Percentage Elongation (PE) was also found to increase with increasing metal mat

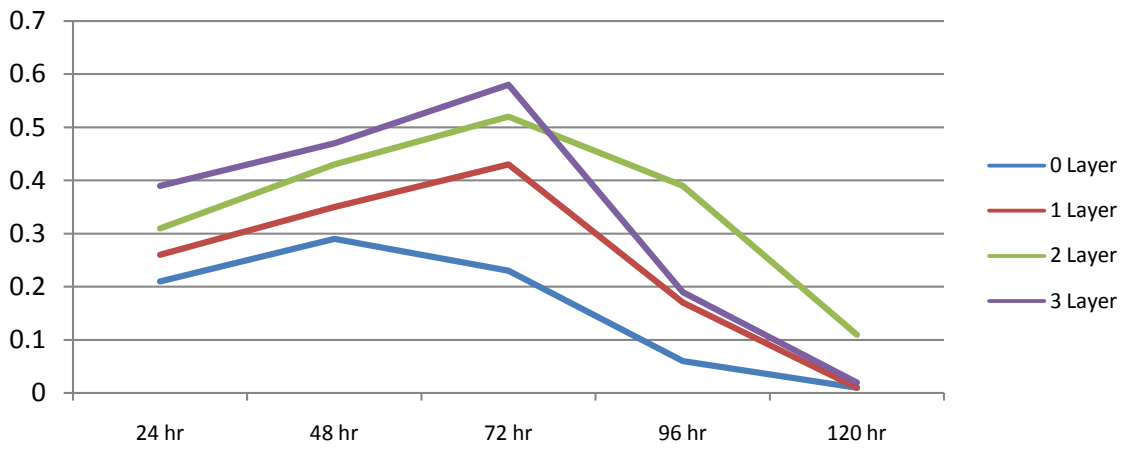

Figure 2. Water absorption of different layered metal mat polyester composite. 
Table 1. Tensile strength of consecutive layer of metal mat in composite.

\begin{tabular}{|c|c|c|c|c|c|}
\hline $\begin{array}{l}\text { Sample } \\
\text { layers }\end{array}$ & Number & Thickness (mm) & Width (mm) & $\begin{array}{c}\text { Tensile strength } \\
(\mathrm{MPa})\end{array}$ & $\begin{array}{l}\text { Mean of tensile } \\
\text { strength (MPa) }\end{array}$ \\
\hline \multirow{3}{*}{0} & S1 & 4 & 21 & 10.20 & \multirow{3}{*}{10.60} \\
\hline & S2 & 4 & 21 & 11.10 & \\
\hline & S3 & 5 & 20 & 10.49 & \\
\hline \multirow{3}{*}{1} & S1 & 5 & 20 & 11.39 & \multirow{3}{*}{11.78} \\
\hline & S2 & 4 & 20 & 11.57 & \\
\hline & S3 & 5 & 23 & 12.38 & \\
\hline \multirow{3}{*}{2} & S1 & 5 & 20 & 12.05 & \multirow{3}{*}{12.14} \\
\hline & S2 & 5 & 21 & 12.14 & \\
\hline & S3 & 5 & 20 & 12.23 & \\
\hline \multirow{3}{*}{3} & S1 & 5 & 20 & 14.76 & \multirow{3}{*}{15.27} \\
\hline & S2 & 5 & 20 & 15.42 & \\
\hline & S3 & 5 & 20 & 15.64 & \\
\hline
\end{tabular}

layer in the composites and it was found to be $4.13 \%$ for the three layered composite and $3.34 \%$ for zero layered one. So, the higher layered metal mat-unsaturated polyester composites were less ductile than low layered ones as shown in Figure 3.

\subsection{Elastic Modulus}

Elastic modulus of the composite, as shown in Figure 4, was found to be very similar to the trend of percent elongation found maximum (378 MPa) for the three layered composite \& minimum (344 MPa) for the zero layered composite. So, the stiffness of the composite increased with the increase of metal mat layer.

\subsection{Flexural Modulus}

Reinforcement provides strength to the composite. So, it is hard to bend the composite with the consecutive increases of metal mat layer. Three mat layered composite gave highest flexural.

Similar results trend was found for flexure modulus of the composites, which was calculated to be $3124 \mathrm{MPa}$ for the three layered composite, $928 \mathrm{MPa}$ for the Zero layered one, as shown in Table 2. A number of studies support current study as it is seen that flexural stress increases with reinforcement [16] [17]. As aluminum wire has higher flexural strength than polyester resin so it increases flexural strength of the composite.

\subsection{Rebound Hardness}

As it is already described that tensile strength, flexural strength increases in the resulting composite with successive increase of metal mat layer. Similar result also found in many study on composites, that is strength increases with reinforcement 


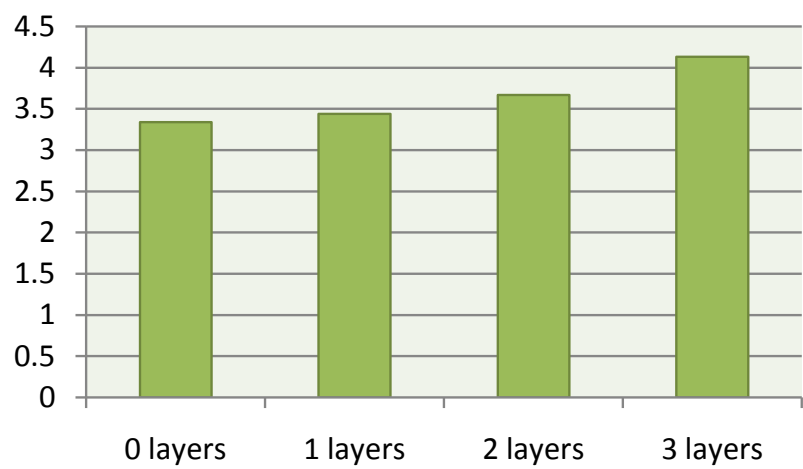

$\square$ Mean elongation \%

Figure 3. Elongation (\%) of differently layered metal mat polyester composite.

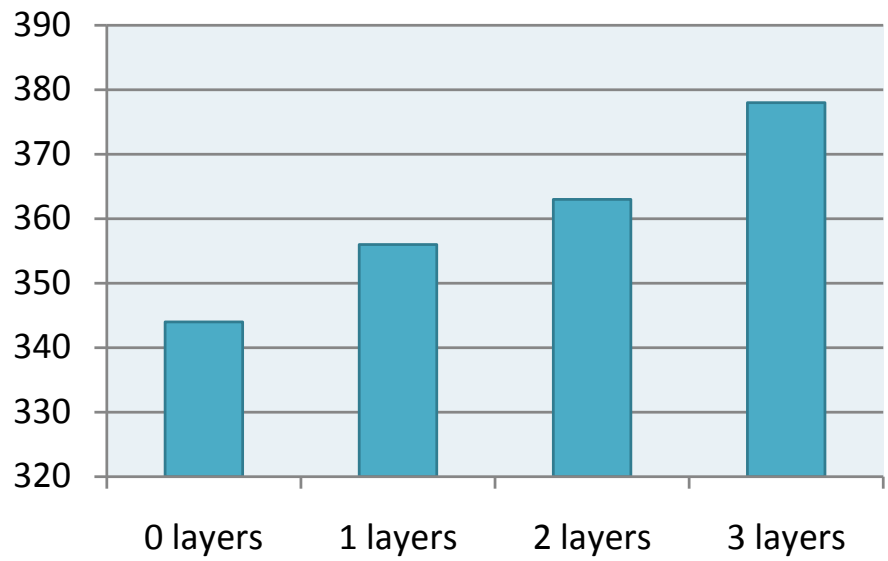

Figure 4. Elastic modulus of differently layered metal mat polyester composite.

Table 2. Flexural modulus of different layered metal-mat polyester composite.

\begin{tabular}{|c|c|c|c|c|c|}
\hline Sample layers & Number & Thickness (mm) & $\begin{array}{l}\text { Width } \\
(\mathrm{mm})\end{array}$ & $\begin{array}{l}\text { Flexural Modulus } \\
\qquad(\mathrm{MPa})\end{array}$ & $\begin{array}{c}\text { Mean of Flexural } \\
\text { Modulus (MPa) }\end{array}$ \\
\hline & S1 & 5 & 22 & 1824 & \\
\hline \multirow[t]{3}{*}{0} & S2 & 5 & 22 & 1949 & 1928 \\
\hline & S3 & 5 & 22 & 2011 & \\
\hline & S1 & 5 & 22 & 2190 & \\
\hline \multirow[t]{3}{*}{1} & S2 & 4 & 23 & 2333 & 2283 \\
\hline & S3 & 5 & 23 & 2326 & \\
\hline & S1 & 5 & 22 & 2454 & \\
\hline \multirow[t]{3}{*}{2} & S2 & 5 & 22 & 2576 & 2556 \\
\hline & S3 & 5 & 22 & 2638 & \\
\hline & S1 & 5 & 22 & 2889 & \\
\hline \multirow[t]{2}{*}{3} & S2 & 5 & 22 & 3097 & 3124 \\
\hline & S3 & 5 & 22 & 3386 & \\
\hline
\end{tabular}

[18]. Therefore, rebound hardness of the samples also increased with the addition of metal mat layer to the composite as shown in Figure 5. 


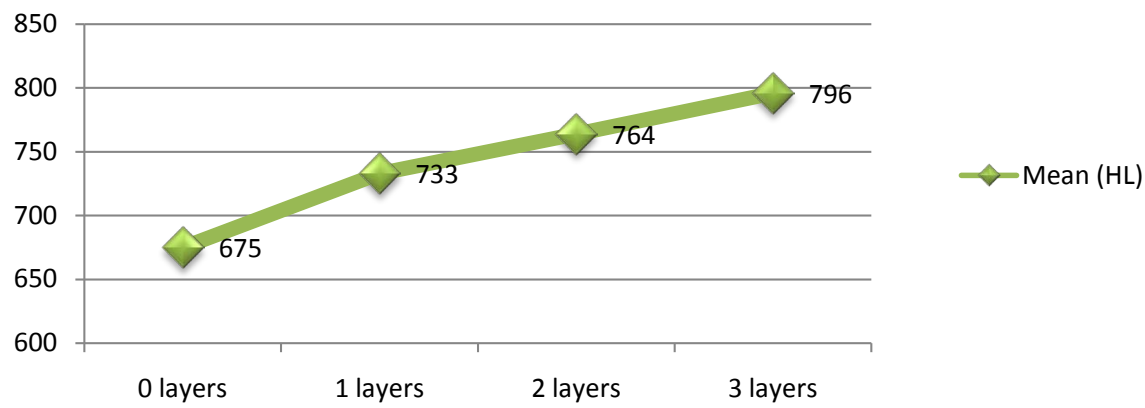

Figure 5. Rebound hardness of differently layered metal-mat polyester composite.

\section{Conclusion}

It was an endeavor to develop a metal mat reinforced polyester composite with a low cost which can be readily used as an alternative structural material to the conventional homogenous material. The mechanical properties found in this study suggested that the resulting composite can be used as a construction material for heavy duty performing households purposes. For long term use, both laboratory and full scale loading tests are required and needed to develop a database for assessment.

\section{Acknowledgements}

The authors acknowledge "Pilot plant and Product development center" of "Bangladesh Council of Scientific and Industrial Research" for their excellent cooperation by allowing using the available facilities in their laboratory.

\section{Conflicts of Interest}

The authors declare no conflicts of interest regarding the publication of this paper.

\section{References}

[1] Chung, D.D.L. (2004) Composite Materials. Kirk-Othmer Encyclopedia of Chemical Technology.

[2] Daniel, I.M. and Ishai, O. (1994) Engineering Mechanics of Composite Materials. Oxford University Press, New York.

[3] Kharrat, M., Carpentier, L., Chateauminois, A. and Kapsa, P. (1997) Evaluation of the Fibre/Matrix Interfacial Strength of a Glass Fibre Rein-Forced Polymer Composite Using a Microindentation Test. Composites Part A, 28, 39-46. https://doi.org/10.1016/S1359-835X(96)00092-9

[4] Vargel and Christian (2004) Corrosion of Aluminium. In: Vargel, C., Ed., Corrosion of Aluminium, Elsevier Science, Oxford, 81-109. https://doi.org/10.1016/B978-008044495-6/50011-2

[5] Learmonth, G.S. and Nesbit, A. (1972) Flammability of Polymers. V. Thermal Volatilization Analysis of Polyester Resin Compositions. British Polymer Journal, 4, 317-325. https://doi.org/10.1002/pi.4980040407

[6] ASTM D790-17 (2017) Standard Test Methods for Flexural Properties of Unrein- 
forced and Reinforced Plastics and Electrical Insulating Materials. ASTM International, West Conshohocken. http://www.astm.org

[7] ASTM D638-14 (2014) Standard Test Method for Tensile Properties of Plastics. ASTM International, West Conshohocken. http://www.astm.org

[8] ASTM D1505-18 (2018) Standard Test Method for Density of Plastics by the Density-Gradient Technique. ASTM International, West Conshohocken. http://www.astm.org

[9] ASTM D570-98 (2018) Standard Test Method for Water Absorption of Plastics. ASTM International, West Conshohocken. http://www.astm.org

[10] Hodgkinson, J.M. (2000) Mechanical Testing of Advanced Fibre Composites. Woodhead Publishing Ltd., Cambridge.

[11] ASTM D790-02 (2002) Standard Test Methods for Flexural Properties of Unreinforced and Reinforced Plastics and Electrical Insulating Materials. ASTM International, West Conshohocken. http://www.astm.org

[12] Shaw, M.C. and Salvo, G.J.D. (1970) On the Plastic Flow beneath a Blunt Axisymmetric Indenter. Transactions of the American Society of Mechanical Engineers, 92, 480.

[13] HARDMEKO (2004) Hardness Measurements Theory and Application in Laboratories and Industries. Washington DC.

[14] Dhakal, H.N., Zhang, Z.Y. and Richardson, M.O.W. (2007) Effect of Water Absorption on the Mechanical Properties of Hemp Fibre Reinforced Unsaturated Polyester Composites. Composites Science and Technology, 67, 1674-1683. https://doi.org/10.1016/j.compscitech.2006.06.019

[15] Li, X., Tabil, L.G., Panigrahi, S. and Crerar, WJ. (2009) The Influence of Fiber Content on Properties of Injection Molded Flax Fiber-HDPE Biocomposites. CSBE/SCGAB 2006 Annual Conference, Edmonton, Paper No. 06-161.

[16] Xu, H.H., Schumacher, G.E, Eichmiller, F.C., Peterson, R.C., Antonucci, J.M., et al. (2003) Continuous-Fiber Preform Reinforcement of Dental Resin Composite Restorations. Dental Materials, 19, 523-530. https://doi.org/10.1016/S0109-5641(02)00100-8

[17] Ellakwa, A.E., Shortall, A.C., Shehata, M.K. and Marquis, P.M. (2001) The Influence of Fibre Placement and Position on the Efficiency of Reinforcement of Fibre Reinforced Composite Bridgework. Journal of Oral Rehabilitation, 28, 785-791. https://doi.org/10.1046/j.1365-2842.2001.00792.x

[18] Ahmad, I., Baharum, A. and Abdullah, I. (2006) Effect of Extrusion Rate and Fiber Loading on Mechanical Properties of Twaron Fiber-Thermoplastic Natural Rubber (TPNR) Composites. Journal of Reinforced Plastics and Composites, 25, 957-965. https://doi.org/10.1177/0731684406065082 